\title{
1 The Genealogical Sorting Index and species delimitation
}

2

Otago

7

${ }^{3}$ Ecology Group, Institute of Agriculture and Environment, Massey University, Palmerston North, New Zealand.

9

*Corresponding Author, email: david.winter@gmail.com 


\section{Abstract}

The Genealogical Sorting Index (gsi) has been widely used in species-delimitation studies, where it is usually interpreted as a measure of the degree to which each of several predefined groups of specimens display a pattern of divergent evolution in a phylogenetic tree. Here we show that the gsi value obtained for a given group is highly dependent on the structure of the tree outside of the group of interest. By calculating the gsi from simulated datasets we demonstrate this dependence undermines some of desirable properties of the statistic. We also review the use of the gsi delimitation studies, and show that the gsi has typically been used under scenarios in which it is expected to produce large and statistically significant results for samples that are not divergent from all other populations and thus should not be considered species. Our proposed solution to this problem performs better than the gsi in under these conditions. Nevertheless, we show that our modified approach can produce positive results for populations that are connected by substantial levels of gene flow, and are thus unlikely to represent distinct species. We stress that the properties of gsi made clear in this manuscript must be taken into account if the statistic is used in speciesdelimitation studies. More generally, we argue that the results of genetic species-delimitation methods need to be interpreted in the light the biological and ecological setting of a study, and not treated as the final test applied to hypotheses generated by other data.

\section{Keywords}

gsi, pairwise-gsi, population genetics, population structure, species delimitation

\section{Introduction}

Genetic sequence data and phylogenetic methods are increasingly being used to aid in the discovery and delimitation of species (reviewed in Fujita et al. 2012). The widespread application of such data and analyses to alpha taxonomy has confirmed that evolutionarily distinct species will not necessarily fall into reciprocally monophyletic groups in phylogenies estimated from DNA sequences. 
Indeed, species can remain paraphyletic with respect to their close relatives in gene trees even millions of years after they begin to diverge (Tajima 1983; Hudson \& Coyne 2002) .

A number of methods have been developed with the objective of delimiting species using such unsorted gene trees (Knowles \& Carstens 2007; O’Meara 2010; Yang \& Rannala 2010, 2014; Ence \& Carstens 2011; Zhang et al. 2011). The increasingly popular use of these methods in empirical species-delimitation studies has inspired a number of methodological papers exploring their statistical properties. These theoretical investigations have shown the methods to be powerful and accurate when their underlying assumptions are met, but it has become clear that violations of these assumptions can generate misleading results (Reid \& Carstens 2012; Carstens et al. 2013; Edwards \& Knowles 2014; Olave et al. 2014). Thus, species delimitation methods are most useful when their statistical properties are understood, and studies can be designed and interpreted in the light of these properties.

Although not exclusively designed for species-delimitation studies, the gsi of Cummings et al. (2008) has been widely used in this context (see references in Table 1). This statistic is a measure of the degree to which a pre-defined group of leaves in a phylogenetic tree falls into an exclusive region in that tree. The value of the statistic ranges from 0 to 1 , with higher values corresponding to more phylogenetic exclusivity. In this way, the gsi aims to bridge the gap between monophyly and paraphyly as categorical terms, and in so doing, quantify the degree to which a lineage has become distinct as a result of evolutionary divergence. The calculation of the gsi is usually accompanied by an hypothesis test, in which the gsi for each group is compared to values calculated from trees in which the tip labels have been permuted.

When compared to other widely used species delimitation methods (Table 2) the gsi has many desirable properties. As well as having power to detect recently diverged lineages, the gsi differs from many comparable methods in not needing, as input parameters, the values of often difficult-toestimate quantities such as the effective population size or mutation rate of the genetic sequences 
under consideration. The gsi value obtained for a given group is also purported to be comparable to those obtained for different groups within the same tree and between those arising from different studies (Cummings et al. 2008).

In applying the gsi to empirical data, however, we have found the value of this statistic to be highly dependent on the structure of the tree outside of the group of interest. This dependence is not reflected in the way the statistic is typically applied and interpreted in species-delimitation studies, and this mismatch between the gsi as it is used and goals of species delimitation undermines the many advantages of the statistic.

\section{The gsi measures exclusivity relative to the entire tree}

An example serves to illustrate the dependence of the gsi obtained for a particular group on the over-all structure of the phylogeny from which it is calculated. Take the tree presented in Figure 1. To calculate gsi for the group "a" in this tree we first need to calculate the intermediate statistic gs, which is defined as

$$
g s=\frac{n}{\sum_{u=1}^{U}\left(d_{u}-2\right)}
$$

where $d_{u}$ is the degree (i.e. the number of connections) of the node $u$, which is one of $U$ total nodes in the smallest sub-tree uniting all members of a group and $n$ is the minimum number of nodes that could be used to unite this group, which is one less than the number of leaves. In the case of Figure $1, n$ is 3, but all 7 nodes in the tree are needed to create a sub-tree uniting group "a". As the tree is fully dichotomous, the degree of each node is 3 . Thus, $g s$ is $3 /(7 \times(3-2))=3 / 7$. To obtain gsi for group "a" the observed value of $g s$ is normalised using the maximum and minimum obtainable value for the statistic given the size of the group and the number of nodes in the tree:

$$
g S i=\frac{\text { observed } g s-\min (g s)}{\max (g s)-\min (g s)}
$$


Here $\max (g s)$ is 1 (the case in which a group is united by the minimum number of nodes, i.e.

monophyly) and $\min (g s)$ is given by the equation

$$
\min (g s)=\frac{n}{\sum_{i=1}^{I}\left(d_{i}-2\right)}
$$

where $d_{i}$ is the degree of node $i$, one of I nodes in the entire tree. Because the smallest sub-tree uniting the group "a" in Figure 1 is the entire tree, $\min (g s)$ for this group is equal to the observed $g s$ value. Thus, the numerator in equation (2) is $3 / 7-3 / 7=0$ and so the value of $g s i$ is also 0 . This result is desirable, as the tree presented in Figure 1 has each group arranged in the least exclusive fashion possible. Nevertheless, defining $\min (g s)$ in this way means the value of $g s i$ is partially dependent on the degree to which other groups in the tree fall into exclusive regions.

Consider now the tree presented in Figure 2, which could be obtained from genetic data underlying the topology illustrated in Figure 1 by simply adding further data from two distantly related taxa. Because the clade containing the "a" and " $b$ " groups is unchanged the observed value of $g s$ for "a" is still 7. The addition of the two groups "c" and " $d$ " to the tree, however, has added 8 new dichotomous nodes. Thus the value of $\min (g s)$ is now $3 /(15 \times(3-2))=3 / 15$ and, following equation (2), gsi is equal to $[3 / 7-3 / 15] /[1-3 / 15] \approx 0.29$. This difference arises from the inclusion of $\min (g s)$ in the calculation of $g s i$, which makes a gsi value obtained for a group a reflection of that group's exclusivity relative to the entire tree. This property is not desirable for a species-delimitation statistic, as it means large gsi values can be obtained for groups that do not represent a population that is divergent from all other samples in a given analysis. Moreover, it also compromises comparisons between groups within one study, or between values obtained from different studies.

A similar issue affects the hypothesis test that is often performed alongside the gsi. Statistical significance, or P-values, arising from this test are usually reported for each of several putative species under consideration in a single analysis. In practice, these P-values are interpreted as the results of independent tests that each group being considered is divergent from all other groups. In 
fact, as Cummings et al. (2008) make clear, because the test is performed by permuting group

assignments across the entire tree, the null hypothesis being tested is that all individuals included in the tree come from a single panmictic population. It is seldom the case that all individuals considered in a species-delimitation study could plausibly have come from a randomly mating population. Thus, statistically significant results may simply represent the rejection of an implausible null hypothesis.

\section{The gsi and species delimitation}

The problems discussed above are most likely to affect interpretation of the gsi when the statistic is calculated for a large number of groups, especially when those groups are likely to be divergent from at least some others under consideration. To determine how often the gsi has been used in such contexts, we performed a literature review (Table 1). We identified papers recorded as citing Cummings et al. (2008) in Web Of Science and Google Scholar. For each study we recorded the context in which the gsi was used, the largest number of groups considered in a single analysis and the criteria by which those groups were determined. The results of this analysis show the gsi has mainly been used in the context of species-delimitation (54 of 78 empirical studies) and that these studies have often applied the statistic to several groups ( mean $=9.9$, median $=6$ ) for which there is a priori evidence for evolutionary divergence. The basis of the group assignment is frequently an existing taxonomic distinction, or a preliminary phylogenetic or clustering analysis performed on data from which the gsi was calculated. Worryingly, these circumstances are exactly those in which (as we show above) use of the gsi can be misleading. We did not find any papers in which the plausibility of the null hypothesis was considered in discussing the statistical significance of results. gsi is likely to be in practice, we calculated the statistic from simulated datasets. We used the program ms (Hudson 2002) to simulate gene trees arising from neutral evolution under the 
diverging at a time point $t$ which was varied among simulations. We performed 500 simulations for each value of $t$ between 0 and $1 N_{e}$ generations in $0.05 \mathrm{~N}_{\mathrm{e}}$ increments, sampling 10 individuals per population in each simulation. For each simulation, we calculated the gsi for group "a" twice, first considering all populations in the simulation (the "four-population tree") then after discarding individuals from the divergent populations " $c$ " and " $d$ " (the "two-population tree"). especially pronounced early in the divergence process, indeed, the expected value of $g s i$ in the fourpopulation case is high (0.40) even when $t=0 N_{e}$ (i.e. when populations " $a$ " and " $b$ " are panmictic with respect to each other). For every simulation, including those in which the " $a$ " and " $b$ " populations were panmictic, the calculation based on the four population-tree produced a significant result. By contrast, calculations based on the two-population tree produced a nearuniform distribution of P-values under panmixia and became increasingly likely to return significant results as the populations diverged.

These simulations confirm that both the value and the significance obtained for the gsi of a given group is partially dependent on the degree to which other groups fall into exclusive regions of the phylogeny being considered. As we note above, this characteristic is not desirable in a statistic purported to relate only to the group under consideration, as it makes comparison of gsi values obtained from different trees problematic. Significant results can readily be obtained from populations that are not genealogically divergent from all others groups in an analysis. 
population-genetic parameters as input. Additionally, the relative simplicity of the gsi means the statistic can be applied to large datasets. Unlike the GMYC (Pons et al., 2006), the gsi can be applied to unsorted gene trees and the gsi can be used to test the validity of proposed species suggested by morphological or other data. Given these unique properties of the gsi, we do no propose that empiricists discarding the statistic entirely. Rather, the properties described here should be carefully considered before the statistic before is applied to datasets.

There are likely to be multiple ways to reasonably incorporate the gsi in particular species delimitation studies; here we propose a general solution that retains the gsi's simplicity but removes its dependence on the overall structure of the tree from which it is calculated. Our proposed statistic, the "mean pairwise gsi" or pwgsi is calculated for a pair of groups, after all tips other than those in the groups of interest have been dropped from the phylogenetic tree under consideration. This approach can be applied to all putative species under consideration in a given study, or only to a subset that are of particular interest.

For example, to analyse the tree and group-assignments depicted in Figure 2 we first produce trees representing the possible pairwise comparisons of groups (Fig 5). For each tree, the pwgsi is simply the mean of the gsi values obtained for these two groups. Thus, in the case of Figure 5 the pwgsi for the "a:b" comparison is 0 and all other comparisons have pwgsi of 1 . This approach requires at most $\left(\begin{array}{l}n \\ 2\end{array}\right)$ values to be calculated, where $n$ is the number of groups being considered. Thus, the pairwise approach is not subject to the computation limitations of methods that consider all possible partitions of a group-assignment (O'Meara 2010; Ence \& Carstens 2011), and can be applied to datasets in which a relatively large number of groups are being considered. It also relatively easy to calculate the pwgsi with the existing GENEALOGICALSORTING software, as we demonstrate in Supplementary Text 1. quantifies each population's exclusivity relative to all other populations. Moreover, the pattern of 
pwgsi values resulting from a single analysis can identify groups that are not divergent with respect to each other, but are divergent from all other groups and thus might be considered part of a single divergent population in subsequent analyses (as is the case with " $a$ " and " $b$ " in example discussed above). This approach uses the same procedure as in the calculation of the two-population scores in

Fig 4. We can infer from Fig 4, therefore, that the pwgsi tracks lineage divergence and a permutation test applied to a particular between-population comparison has a strong power to detect divergent groups.

\section{pwgsi and population structure}

The high power of the pwgsi to detect an exclusive distribution of tips on a phylogeny may seem to make it an ideal statistic for species delimitation in the presence of incomplete lineage sorting. divergence required to obtain significant results means that such results can be obtained even for what may turn out to be transient isolation between populations. Moreover, speciation is not the only one way in which a non-random distribution of groups might occur on a phylogeny. Specifically, sub-populations within a population with some degree of genetic structuring may be expected to fall into partially exclusive regions of a gene tree. To investigate the degree to which population

* Note, the inclusion of population " $c$ " in this design illustrates the importance of the pw-gsi approach to quantifying lineage divergence. As this simulation proceeds population " $c$ " is expected to become increasingly exclusive in gene trees arising from this history; thus the gsi values of " $a$ " and " $b$ " will increase over the course of the simulation, even when these populations are panmictic with respect to each other. 

between these populations decreased (and thus the populations became more structured) (Fig 7). We also investigated the power of the pwgsi to detect population structure in these simulations by performing $10^{4}$ group-label permutations per simulation. Significant results were obtained even with a P-value $<0.05$ generally accepted even a small number of successful migrants are enough to prevent speciation in the absence of selection (Slatkin 1995; Gavrilets 2000). Speciation is only possible with greater rates of migration when very strong divergent selection is acting (Felsenstein 1981; Kirkpatrick \& Ravigné 2002). Clearly then, the results of the pwgsi cannot be treated as unambiguous evidence that the groups being considered are different species. Rather, researchers need to consider it in the design of their studies and the interpretation of results. In particular, the pwgsi may be a poor choice of statistic if a putative species is known to have a distinct geographic distribution with respect to others to which it is being compared (or if the population samples being analysed come from different regions).

By contrast, our finding that the pwgsi measures population structure may make it a useful et al. 1992) that is currently widely used for sequence data in this context. Indeed, the gsi has already been used in this context (Chen \& Hare 2011; Gustafsson \& Olsson 2012).

\section{Conclusions}


Genetic sequences are a potentially powerful source of data for the discovery and delimitation of species. The results reported above, however, emphasise the care that needs to be taken in interpreting the results of DNA-based species-delimitation methods. We have shown that a naïve interpretation of $g s i$, a statistic that has been widely used in species-delimitation studies, can lead to erroneous conclusions. Although the gsi remains powerful approach to species when applied significant results from populations connected by substantial gene flow. biological and ecological setting of a study, rather than as final arbiters of species' status applied to hypotheses generated by other data.

\section{Acknowledgements}

We thank three anonymous reviewers, Steffen Klaere, Giulio Dalla Riva, and Michael Cummings, whose comments on this manuscript greatly improved it. SK in particular should be credited with the insight described in the footnote on $\mathrm{pgX}$. 


\section{References}

244 Almendra AL, Rogers DS, González-Cózatl FX (2014) Molecular phylogenetics of the Handleyomys chapmani complex in Mesoamerica. Journal of Mammalogy, 95, 26-40.

Ardila NE, Giribet G, Sánchez JA (2012) A time-calibrated molecular phylogeny of the precious corals: reconciling discrepancies in the taxonomic classification and insights into their evolutionary history. BMC Evolutionary Biology, 12, 246.

Ashalakshmi NC, Nag KSC, Karanth KP (2014) Molecules support morphology: species status of South Indian populations of the widely distributed Hanuman langur. Conservation Genetics, 16, 4358.

Bagley JC, Alda F, Breitman MF et al. (2015) Assessing species boundaries using multilocus species delimitation in a morphologically conserved group of neotropical freshwater fishes, the Poecilia sphenops species complex (Poeciliidae) PLOS ONE, 10, e0121139.

Bon M-C, Hoelmer KA, Pickett CH et al. (2015) Populations of Bactrocera oleae (Diptera: Tephritidae) and Its Parasitoids in Himalayan Asia. Annals of the Entomological Society of America, sav114.

Boykin LM, Schutze MK, Krosch MN et al. (2014) Multi-gene phylogenetic analysis of south-east Asian pest members of the Bactrocera dorsalis species complex (Diptera: Tephritidae) does not support current taxonomy. Journal of Applied Entomology, 138, 235-253.

Camargo A, Morando M, Avila LJ, Sites JW Jr (2012) Species delimitation with ABC and other coalescent-based methods: a test of accuracy with simulations and an empirical example Ecology, 22, 4369-4383.

Cesar S. Herrera CL (2013) Revision of the genus Corallomycetella with Corallonectria gen. nov. for $C$. jatrophae (Nectriaceae, Hypocreales). Mycosystema, 32, 518-544. 
Chen G, Hare MP (2011) Cryptic diversity and comparative phylogeography of the estuarine copepod Acartia tonsa on the US Atlantic coast. Molecular Ecology, 20, 2425-2441.

Corcoran P, Dettman JR, Sun Y et al. (2014) A global multilocus analysis of the model fungus Neurospora reveals a single recent origin of a novel genetic system. Molecular Phylogenetics and Evolution, 78, 136-147.

Costanzo KS, Taylor DJ (2010) Rapid ecological isolation and intermediate genetic divergence in lacustrine cyclic parthenogens. BMC Evolutionary Biology, 10, 166.

Cummings MP, Neel MC, Shaw KL (2008) A genealogical approach to quantifying lineage divergence. Evolution, 62, 2411-2422.

Davison A, Chiba S, Barton NH, Clarke B (2005) Speciation and Gene Flow between Snails of Opposite Chirality. PLoS Bioogyl, 3, e282.

Derkarabetian S, Hedin M (2014) Integrative taxonomy and species delimitation in harvestmen: a revision of the western North American genus Sclerobunus (Opiliones: Laniatores: Travunioidea) (W Arthofer, Ed,). PLOS ONE, 9, e104982.

Donald KM, Preston J, Williams ST et al. (2012) Phylogenetic relationships elucidate colonization patterns in the intertidal grazers Osilinus Philippi, 1847 and Phorcus Risso, 1826 (Gastropoda: Trochidae) in the northeastern Atlantic Ocean and Mediterranean Sea. Molecular Phylogenetics and Evolution, 62, 35-45.

Doyle VP, Oudemans PV, Rehner SA, Litt A (2013) Habitat and host indicate lineage identity in Colletotrichum gloeosporioides s.l. from wild and agricultural landscapes in North America. PLOS ONE, 8, e62394.

Edwards DL, Knowles LL (2014) Species detection and individual assignment in species delimitation: can integrative data increase efficacy? Proceedings of the Royal Society of London B: Biological Sciences, 281, 20132765. 
Egea E, David B, Choné T et al. (2016) Morphological and genetic analyses reveal a cryptic species complex in the echinoid Echinocardium cordatum and rule out a stabilizing selection explanation. Molecular Phylogenetics and Evolution, 94, 207-220.

Emelianov I, Marec F, Mallet J (2004) Genomic evidence for divergence with gene flow in host races of the larch budmoth. Proceedings of the Royal Society B: Biological Sciences, 271, 97-105.

Ence DD, Carstens BC (2011) SpedeSTEM: a rapid and accurate method for species delimitation. Molecular Ecology Resources, 11, 473-480.

Escobar D, Zea S, Sánchez JA (2012) Phylogenetic relationships among the Caribbean members of the Cliona viridis complex (Porifera, Demospongiae, Hadromerida) using nuclear and mitochondrial DNA sequences. Molecular Phylogenetics and Evolution, 64, 271-284.

Esposito LA, Bloom T, Caicedo-Quiroga L et al. (2015) Islands within islands: diversification of tailless whip spiders (Amblypygi, Phrynus) in Caribbean caves. Molecular Phylogenetics and Evolution, 93, 107-117.

Faustová M, Sacherová V, Sheets HD, Svensson J-E, Taylor DJ (2010) Coexisting Cyclic Parthenogens Comprise a Holocene Species Flock in Eubosmina. PLoS ONE, 5, e11623.

Felsenstein J (1981) Skepticism towards Santa Rosalia, or why are there so few kinds of animals? Evolution, 124-138.

Fernández-Mazuecos M, Vargas P (2014) Quaternary radiation of bifid toadflaxes (Linaria sect. Versicolores) in the Iberian Peninsula: low taxonomic signal but high geographic structure of plastid DNA lineages. Plant Systematics and Evolution, 301, 1411-1423.

Fourie A, Wingfield MJ, Wingfield BD, Barnes I (2014) Molecular markers delimit cryptic species in Ceratocystis sensu stricto. Mycological Progress, 14, 1020.

Fujita MK, Leaché AD, Burbrink FT, McGuire JA, Moritz C (2012) Coalescent-based species delimitation in an integrative taxonomy. Trends in ecology \& evolution, 27, 480-488. 
Fusinatto LA, Alexandrino J, Haddad CFB et al. (2013) Cryptic Genetic diversity is paramount in smallbodied amphibians of the genus Euparkerella (Anura: Craugastoridae) endemic to the Brazilian Atlantic forest (D Fontaneto, Ed,). PLoS ONE, 8, e79504.

Gavrilets S (2000) Waiting time to parapatric speciation. Proceedings of the Royal Society B: Biological Sciences, 267, 2483-2492.

Gazis R, Rehner S, Chaverri P (2011) Species delimitation in fungal endophyte diversity studies and its implications in ecological and biogeographic inferences. Molecular Ecology, 20, 30013013.

Gehesquière B, Crouch JA, Marra RE et al. (In Press) Characterization and taxonomic reassessment of

Hendrixson BE, DeRussy BM, Hamilton CA, Bond JE (2013) An exploration of species boundaries in turret-building tarantulas of the Mojave Desert (Araneae, Mygalomorphae, Theraphosidae,

Groeneveld LF, Blanco MB, Raharison J-L et al. (2010) MtDNA and nDNA corroborate existence of sympatric dwarf lemur species at Tsinjoarivo, eastern Madagascar. Molecular Phylogenetics and Evolution, 55, 833-845.

Gustafsson DR, Olsson U (2012) Flyway homogenisation or differentiation? Insights from the phylogeny of the sandpiper (Charadriiformes: Scolopacidae: Calidrinae) wing louse genus Lunaceps (Phthiraptera: Ischnocera). International Journal for Parasitology, 42, 93-102. based on chloroplast and nuclear DNA barcodes. Taxon, 64, 714-726. 
Jones G, Aydin Z, Oxelman B (2015) DISSECT: an assignment-free Bayesian discovery method for species delimitation under the multispecies coalescent. Bioinformatics, 31, 991-998.

Keith R, Hedin M (2012) Extreme mitochondrial population subdivision in southern Appalachian paleoendemic spiders (Araneae: Hypochilidae: Hypochilus), with implications for species delimitation. Journal of Arachnology, 40, 167-181.

Kirkpatrick M, Ravigné V (2002) Speciation by natural and sexual selection: models and experiments. The American Naturalist, 159, S22-S35.

Knowles LL, Carstens BC (2007) Delimiting species without monophyletic gene trees. Systematic Biology, 56, 887-895.

Koopman MM, Baum DA (2010) Isolating nuclear genes and identifying lineages without monophyly: an example of closely related species from southern Mmadagascar. International Journal of Plant Sciences, 171, 761-771.

De León LF, Bermingham E, Podos J, Hendry AP (2010) Divergence with gene flow as facilitated by ecological differences: within-island variation in Darwin's finches. Philosophical Transactions of the Royal Society B: Biological Sciences, 365, $1041-1052$.

Levsen ND, Tiffin P, Olson MS (2012) Pleistocene Speciation in the Genus Populus (Salicaceae). Systematic Biology, 61, 401-412.

Lopes JS, Balding D, Beaumont MA (2009) PopABC: a program to infer historical demographic parameters. Bioinformatics, 25, 2747-2749.

Lu B, Bi K, Fu J (2014) A phylogeographic evaluation of the Amolops mantzorum species group: Cryptic species and plateau uplift. Molecular Phylogenetics and Evolution, 73, 40-52.

Martinsson S, Rhodén C, Erséus C (In press) Barcoding gap, but no support for cryptic speciation in resolves the pseudo-cryptic complex of the disjunct epiphytic moss Orthotrichum consimile s.I. (Orthotrichaceae). Taxon, 61, 1180-1198. 
Niemiller ML, Fitzpatrick BM, Miller BT (2008) Recent divergence with gene flow in Tennessee cave salamanders (Plethodontidae: Gyrinophilus) inferred from gene genealogies. Molecular Ecology, 17, 2258-2275.

Niemiller ML, McCandless JR, Reynolds RG et al. (2013) Effects of climatic and geological processes during the pleistocene on the evolutionary history of the northern cavefish, Amblyopsis spelaea (Teleostei: Amblyopsidae). Evolution, 67, 1011-1025.

Niemiller ML, Near TJ, Fitzpatrick BM (2012) Delimiting species using multilocus data: diagnosing cryptic diversity in the southern cavefish, Typhlichthys subterraneus (Teleostei: Amblyopsidae). Evolution, 66, 846-866.

Nosil P (2008) Speciation with gene flow could be common. Molecular Ecology, 17, 2103-2106.

Olave M, Solà E, Knowles LL (2014) Upstream analyses create problems with dna-based species delimitation. Systematic Biology, 63, 263-271.

O’Meara BC (2010) New heuristic methods for joint species delimitation and species tree inference. Systematic Biology, 59, 59-73.

Parmakelis A, Kotsakiozi P, Stathi I, Poulikarakou S, Fet V (2013) Hidden diversity of Euscorpius (Scorpiones: Euscorpiidae) in Greece revealed by multilocus species-delimitation approaches. Biological journal of the Linnean Society, 110, 728-748.

Pažoutová S, Pešicová K, Chudíčková M, utka PŠ, Kolařík M (2015) Delimitation of cryptic species inside Claviceps purpurea. Fungal Biology, 119, 7-26.

Pérez G, Burgess TI, Slippers B et al. (2013) Teratosphaeria pseudonubilosa sp. nov., a serious Eucalyptus leaf pathogen in the Teratosphaeria nubilosa species complex. Australasian Plant Pathology, 43, 67-77.

Pettengill JB, Moeller DA (2012) Tempo and mode of mating system evolution between incipient Clarkia species: temporal dynamics of mating system evolution. Evolution, 66, 1210-1225. 
Pino-Bodas R, Ahti T, Stenroos S, Martin MP, Burgaz AR (2013) Multilocus approach to species recognition in the Cladonia humilis complex (Cladoniaceae, Ascomycota). American Journal of Botany, 100, 664-678.

Pons J, Barraclough TG, Gomez-Zurita J et al. (2006) Sequence-based species delimitation for the DNA taxonomy of undescribed insects. Systematic biology, 55, 595-609.

Prévot V, Jordaens K, Sonet G, Backeljau T (2013) Exploring species level taxonomy and species delimitation methods in the facultatively self-fertilizing land snail genus Rumina (Gastropoda: Pulmonata). PLOS ONE, 8, e60736.

Ramirez JL, Miyaki CY, Frederick PC, Lama SND (2014) Species delimitation in the genus Eudocimus (Threskiornithidae: Pelecaniformes): first genetic approach. Waterbirds, 37, 419-425.

Reid NM, Carstens BC (2012) Phylogenetic estimation error can decrease the accuracy of species delimitation: a Bayesian implementation of the general mixed Yule-coalescent model. BMC Evolutionary Biology, 12, 196.

Sakalidis ML, Hardy GESJ, Burgess TI (2011) Use of the Genealogical Sorting Index (GSI) to delineate species boundaries in the Neofusicoccum parvum-Neofusicoccum ribis species complex. Molecular Phylogenetics and Evolution, 60, 333-344.

Salariato DL, Zuloaga FO, AI-Shehbaz IA (2012) Morphometric studies and taxonomic delimitation in Menonvillea scapigera and related species (Cremolobeae: Brassicaceae). Plant Systematics and Evolution, 298, 1961-1976.

Sánchez-Ramírez S, Tulloss RE, Guzmán-Dávalos L et al. (In Press) In and out of refugia: historical patterns of diversity and demography in the North American Caesar's mushroom species complex. Molecular Ecology.

Schmidt-Lebuhn AN, de Vos JM, Keller B, Conti E (2012) Phylogenetic analysis of Primula section Primula reveals rampant non-monophyly among morphologically distinct species. Molecular Phylogenetics and Evolution, 65, 23-34. 
Slatkin M (1995) A measure of population subdivision based on microsatellite allele frequencies. Genetics, 139, 457.

Su X, Wu G, Li L, Liu J (2015) Species delimitation in plants using the Qinghai-Tibet Plateau endemic Orinus (Poaceae: Tridentinae) as an example. Ann Bot, 116, 35-48.

Tajima F (1983) Evolutionary relationship of DNA sequences in finite populations. Genetics, 105, 437-460.

Taole MM, Burgess TI, Gryzenhout M, Wingfield BD, Wingfield MJ (2011) DNA sequence incongruence and inconsistent morphology obscure species boundaries in the Teratosphaeria suttonii species complex. Mycoscience, 53, 270-283.

Udayanga D, Castlebury LA, Rossman AY, Hyde KD (2014) Species limits in Diaporthe: molecular reassessment of D. citri, D. cytosporella, D. foeniculina and D. rudis. Persoonia - Molecular Phylogeny and Evolution of Fungi, 32, 83-101.

Valcárcel V, Vargas P (2010) Quantitative morphology and species delimitation under the general lineage concept: Optimization for Hedera (Araliaceae). American Journal of Botany, 97, $1555-1573$.

Vigalondo B, Fernández-Mazuecos M, Vargas P, Sáez L (2015) Unmasking cryptic species: morphometric and phylogenetic analyses of the Ibero-North African Linaria incarnata complex. Botanical Journal of the Linnean Society, 177, 395-417.

Viricel A, Rosel PE (2014) Hierarchical population structure and habitat differences in a highly mobile marine species: the Atlantic spotted dolphin. Molecular Ecology, 23, 5018-5035.

Walker DM, Castlebury LA, Rossman AY, White Jr. JF (2012) New molecular markers for fungal phylogenetics: Two genes for species-level systematics in the Sordariomycetes (Ascomycota). Molecular Phylogenetics and Evolution, 64, 500-512.

Walstrom VW, Klicka J, Spellman GM (2012) Speciation in the White-breasted Nuthatch (Sitta carolinensis): a multilocus perspective. Molecular Ecology, 21, 907-920. 
Wang X, Zang R, Yin Z, Kang Z, Huang L (2014) Delimiting cryptic pathogen species causing apple

Weisrock DW, Rasoloarison RM, Fiorentino I et al. (2010) Delimiting species without nuclear monophyly in Madagascar's mouse lemurs. PLoS ONE, 5, e9883.

Willyard A, Wallace LE, Wagner WL et al. (2011) Estimating the species tree for Hawaiian Schiedea Phylogenetics and Evolution, 60, 29-48.

Yang Z, Rannala B (2010) Bayesian species delimitation using multilocus sequence data. Proceedings of the National Academy of Sciences, 107, 9264-9269.

Yang Z, Rannala B (2014) Unguided Species Delimitation Using DNA Sequence Data from Multiple Loci. Molecular Biology and Evolution, 31, 3125-3135.

Zhang C, Zhang D-X, Zhu T, Yang Z (2011) Evaluation of a Bayesian Coalescent Method of Species Delimitation. Systematic Biology, 60, 747-761. 
Table 1

\begin{tabular}{|c|c|c|}
\hline Reference & Evidence for group assignment & $\begin{array}{l}\mathrm{n} . \\
\text { groups }\end{array}$ \\
\hline Martinsson et al. In press & Clades in mitochondrial gene tree & 2 \\
\hline Sánchez-Ramírez et al. In Press & Existing taxonomic distinction, clades in gene trees & 17 \\
\hline Gehesquière et al. In Press & Clustering of haplotypes & 2 \\
\hline Egea et al. 2016 & Mitochondrial clades & 5 \\
\hline Bon et al. 2015 & Existing taxonomic distinction & 3 \\
\hline Hu et al. 2015 & Clades identified in other trees & 7 \\
\hline Esposito et al. 2015 & Clustering of haplotypes & 11 \\
\hline Su et al. 2015 & Clustering of haplotypes & 3 \\
\hline Bagley et al. 2015 & Clades, other delimitation methods, existing taxonomic distinction & 10 \\
\hline Vigalondo et al. 2015 & Clades in multilocus phylogeny and existing taxonomic distinction & 4 \\
\hline Pažoutová et al. 2015 & Existing taxonomic distinction & 4 \\
\hline Ramirez et al. 2014 & Existing taxonomic distinction & 2 \\
\hline Fourie et al. 2014 & Existing taxonomic distinction and geographically isolated populations & 17 \\
\hline Fernández-Mazuecos \& Vargas 2014 & Existing taxonomic distinction & 6 \\
\hline Viricel \& Rosel 2014 & Morphology, clustering of genotypic data and geographic distribution & 2 \\
\hline Derkarabetian \& Hedin 2014 & Morphology, mitochondrial clades & 11 \\
\hline Wang et al. 2014 & Existing taxonomic distinction, clades in gene trees & 3 \\
\hline Ashalakshmi et al. 2014 & Existing taxonomic distinction & 4 \\
\hline Udayanga et al. 2014 & Existing taxonomic distinction and congruent clades among gene trees & 10 \\
\hline Almendra et al. 2014 & Existing taxonomic distinction and clades in gene trees & 3 \\
\hline Lu et al. 2014 & Clades in a multi-locus phylogeny & 8 \\
\hline Corcoran et al. 2014 & Clustering of haplotypes & 11 \\
\hline Boykin et al. 2014 & Existing taxonomic distinction and clades in consensus tree & 39 \\
\hline Fusinatto et al. 2013 & Clades in a multi-locus phylogeny & 6 \\
\hline Pérez et al. 2013 & ITS clades & 2 \\
\hline Parmakelis et al. 2013 & Clades in a multi-locus phylogeny & 16 \\
\hline Doyle et al. 2013 & Clades supported in $>=3$ of 4 gene trees & 16 \\
\hline Pino-Bodas et al. 2013 & Existing taxonomic distinction and morphological differences & 9 \\
\hline Prévot et al. 2013 & Clades in COI gene tree or combined mitochondrial tree & 8 \\
\hline Zhao et al. 2013 & Existing taxonomic distinction & 6 \\
\hline Cesar S. Herrera 2013 & Existing taxonomic distinction and geographic distribution & 4 \\
\hline Niemiller et al. 2013 & Existing taxonomic distinction and geographic distribution & 4 \\
\hline Hendrixson et al. 2013 & Existing taxonomic distinction and clades in mitochondrial gene tree & 4 \\
\hline Keith \& Hedin 2012 & Existing taxonomic distinction and geographic distribution & 76 \\
\hline Niemiller et al. 2012 & Species delimitation/assignment via Brownie & 19 \\
\hline Ardila et al. 2012 & Existing taxonomic distinction & 13 \\
\hline Walker et al. 2012 & Existing taxonomic distinction & 11 \\
\hline Donald et al. 2012 & Existing taxonomic distinction and geographic distribution & 9 \\
\hline Walstrom et al. 2012 & Geographic distribution & 7 \\
\hline Schmidt-Lebuhn et al. 2012 & Existing taxonomic distinction & 6 \\
\hline Escobar et al. 2012 & Existing taxonomic distinction & 6 \\
\hline Medina et al. 2012 & Morphological differences & 4 \\
\hline Salariato et al. 2012 & Existing taxonomic distinction & 2 \\
\hline
\end{tabular}



available under aCC-BY 4.0 International license.

Pettengill \& Moeller 2012

Levsen et al. 2012

Willyard et al. 2011

Gazis et al. 2011

Taole et al. 2011

Sakalidis et al. 2011

Weisrock et al. 2010

Faustová et al. 2010

Groeneveld et al. 2010

Valcárcel \& Vargas 2010

Koopman \& Baum 2010

Costanzo \& Taylor 2010
Existing taxonomic distinction

Existing taxonomic distinction 2

Existing taxonomic distinction 32

Clades in consensus tree 16

Clades in ITS gene tree $\quad 14$

Existing taxonomic distinction and morphological differences 8

$\begin{array}{ll}\text { Existing taxonomic distinction and geographic distribution } & 16\end{array}$

Existing taxonomic distinction and geographic distribution 8

Existing taxonomic distinction and morphological differences 4

Existing taxonomic distinction 4

Existing taxonomic distinction 3

Existing taxonomic distinction $\quad 2$

463 Summary of papers in which the gsi is principally used for species delimitation. "n.groups" refers to

464 the greatest number of putative species considered in a single analysis 


\begin{tabular}{|c|c|c|c|c|}
\hline Method & Primary input & Group assignment & Other parameters & Result \\
\hline $\begin{array}{l}\text { DISSECT (Jones et } \\
\text { al. 2015) }\end{array}$ & Alignments & Inferred & $\theta, \tau, \omega, \lambda, \mu$ & Posterior distribution of model-paramaters, including species-tree and species- delimitation \\
\hline $\begin{array}{l}\text { BPP (Yang \& } \\
\text { Rannala 2010, } \\
\text { 2014) }\end{array}$ & Alignments & A priori & $\theta, \tau$, species tree* & Posterior probability that species tree nodes represent speciation events \\
\hline $\begin{array}{l}\text { popABC (Lopes et } \\
\text { al. 2009; Camargo } \\
\text { et al. 2012) }\end{array}$ & Alignments & A priori & $\theta, \tau$, species tree & Posterior probability that species tree nodes represent speciation events \\
\hline $\begin{array}{l}\text { SpedeSTEM (Ence } \\
\& \text { Carstens 2011) }\end{array}$ & Gene trees & A priori & $\theta$ & Likelihood for population-delimitation models \\
\hline $\begin{array}{l}\text { Brownie (O'Meara } \\
\text { 2010) }\end{array}$ & Gene trees & Inferred & None & Joint inference of maximum likelihood species-tree and species-delimitation \\
\hline $\begin{array}{l}\text { GMYC (Pons et al. } \\
\text { 2006) }\end{array}$ & Gene tree & Inferred & None & Likelihood for species-delimitation models \\
\hline gsi [14] & Gene tree & A priori & None & Statistic and hypothesis-test measuring each group's phylogenetic exclusivity \\
\hline
\end{tabular}

466

468 specifies a prior on the on the number of species present in a dataset, and $\lambda$ and $\mu$ represent the speciation and extinction rates of a birth-death processes

469 generating the underlying species tree. The description of the popABC approach to species delimitation refers specifically to the method employed by

470 Camargo et al (Camargo et al. 2012)

$471 \quad *$ Note the species tree is an optional input parameter for BPP 


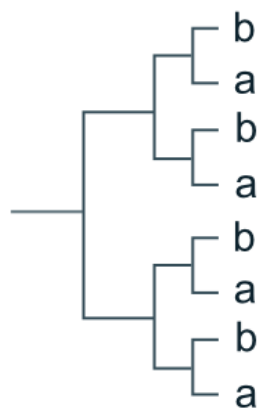

Figure 1

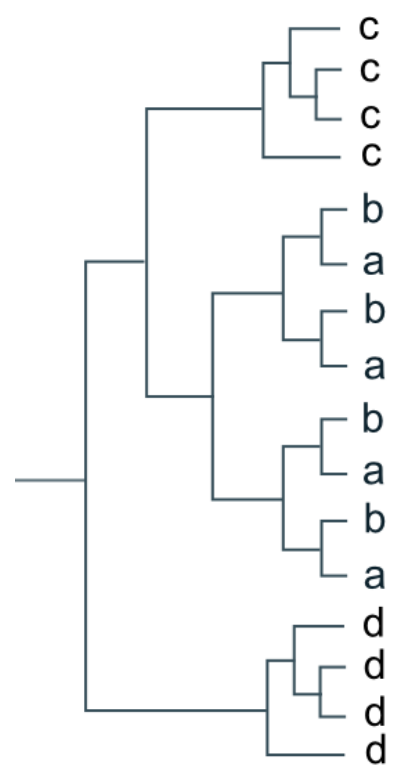

\section{$476 \quad$ Figure 2}

Hypothetical phylogenetic tree, obtained by adding two additional groups (" $c$ " and " $d$ ") to the tree presented in Figure 2. 


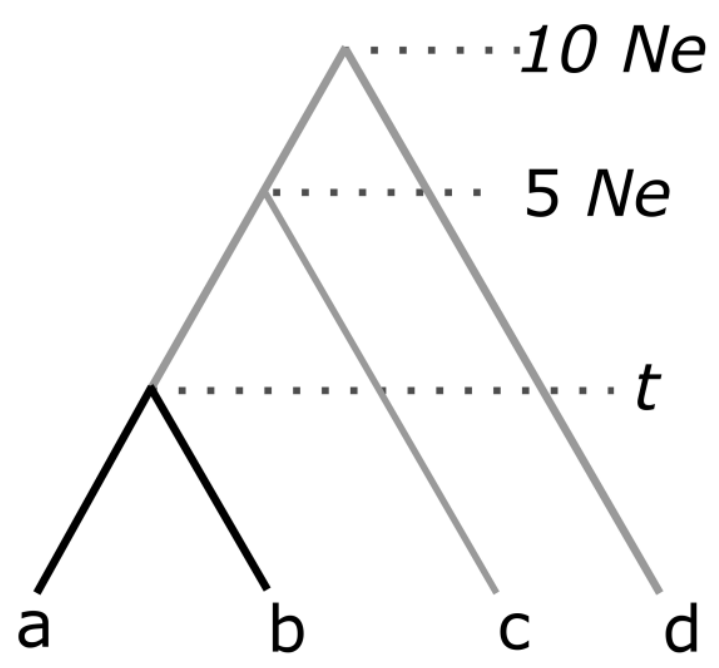

480

Figure 3

Demographic history under which simulations were performed. In each simulation gsi was "d" had been dropped (the two-population tree). 

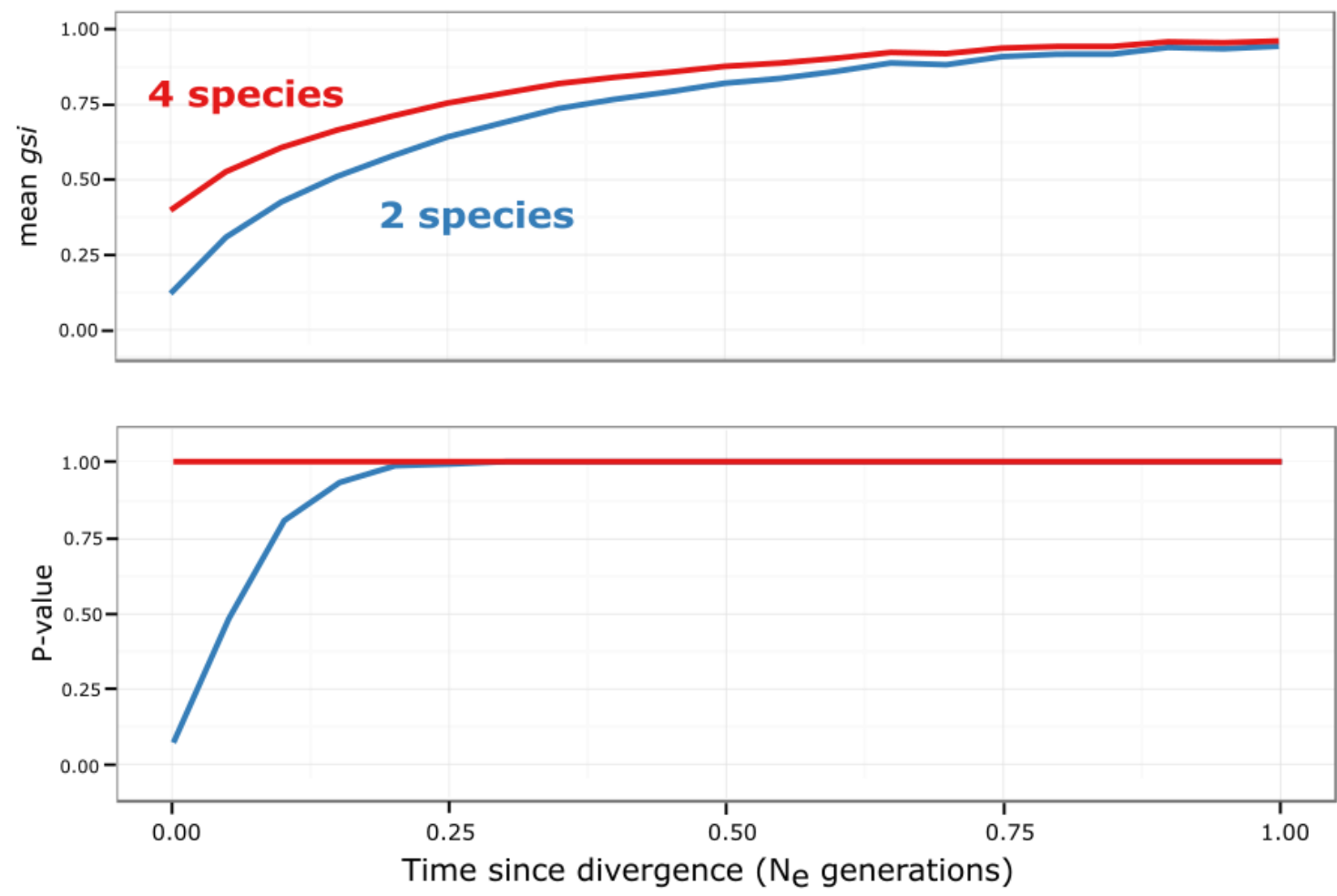

Figure 4

Above: The gsi value obtained for a group depends on the overall structure of the tree from which it is calculated. The red line represents the mean gsi value calculated for group "a" in the simulation depicted in Figure 3 when the all four populations are included in the calculation. The blue line is the mean gsi calculated for the same population when the divergent populations " $\mathrm{c}$ " and "d" are first discarded.

Below: The hypothesis test usually performed alongside the calculation of gsi readily produces significant results for populations that are not divergent from all other populations. The red line represents the proportion of simulations in which population "a" was found to have a significant pattern of exclusivity in the four-population tree. The blue line represents the same proportion calculated from the two-population tree. 
b

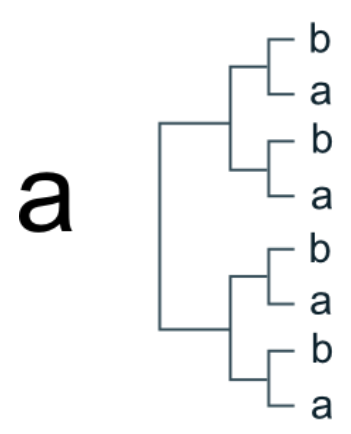

b

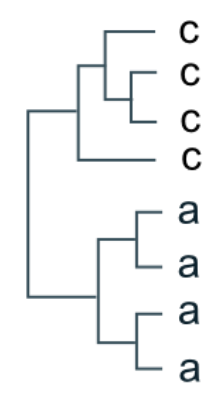

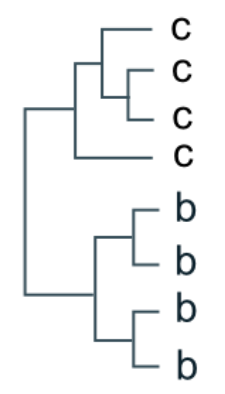

C

Figure 5 
bioRxiv preprint doi: https://doi.org/10.1101/036525; this version posted January 12,2016 . The copyright holder for this preprint (which was not certified by peer review) is the author/funder, who has granted bioRxiv a license to display the preprint in perpetuity. It is made available under aCC-BY 4.0 International license.

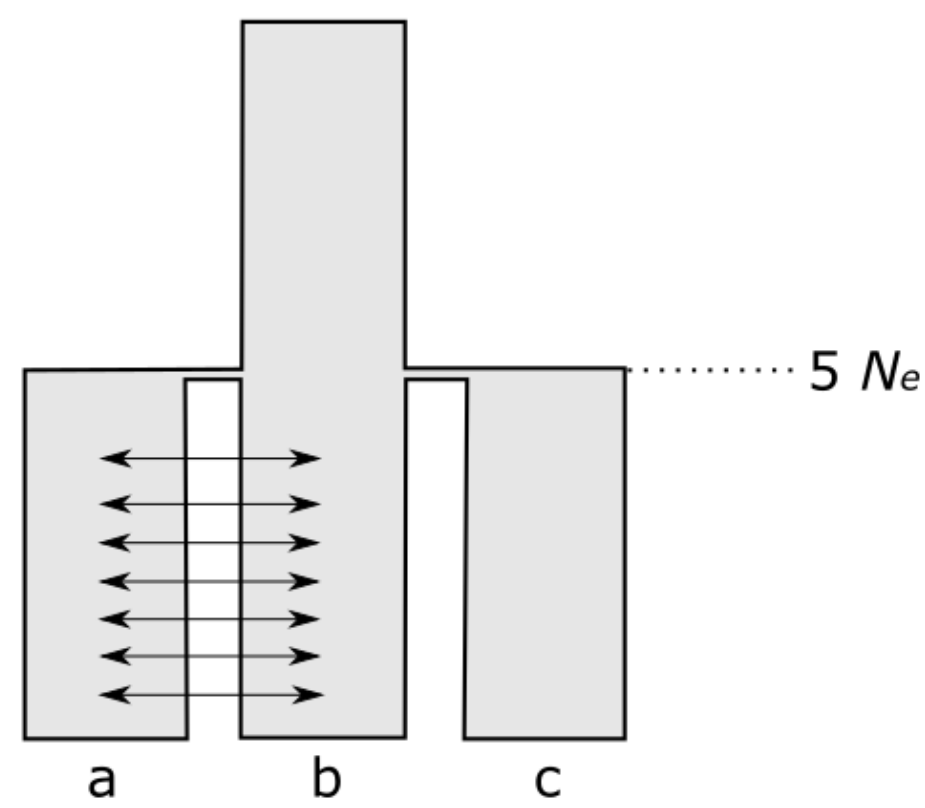

Figure 6 generations. 

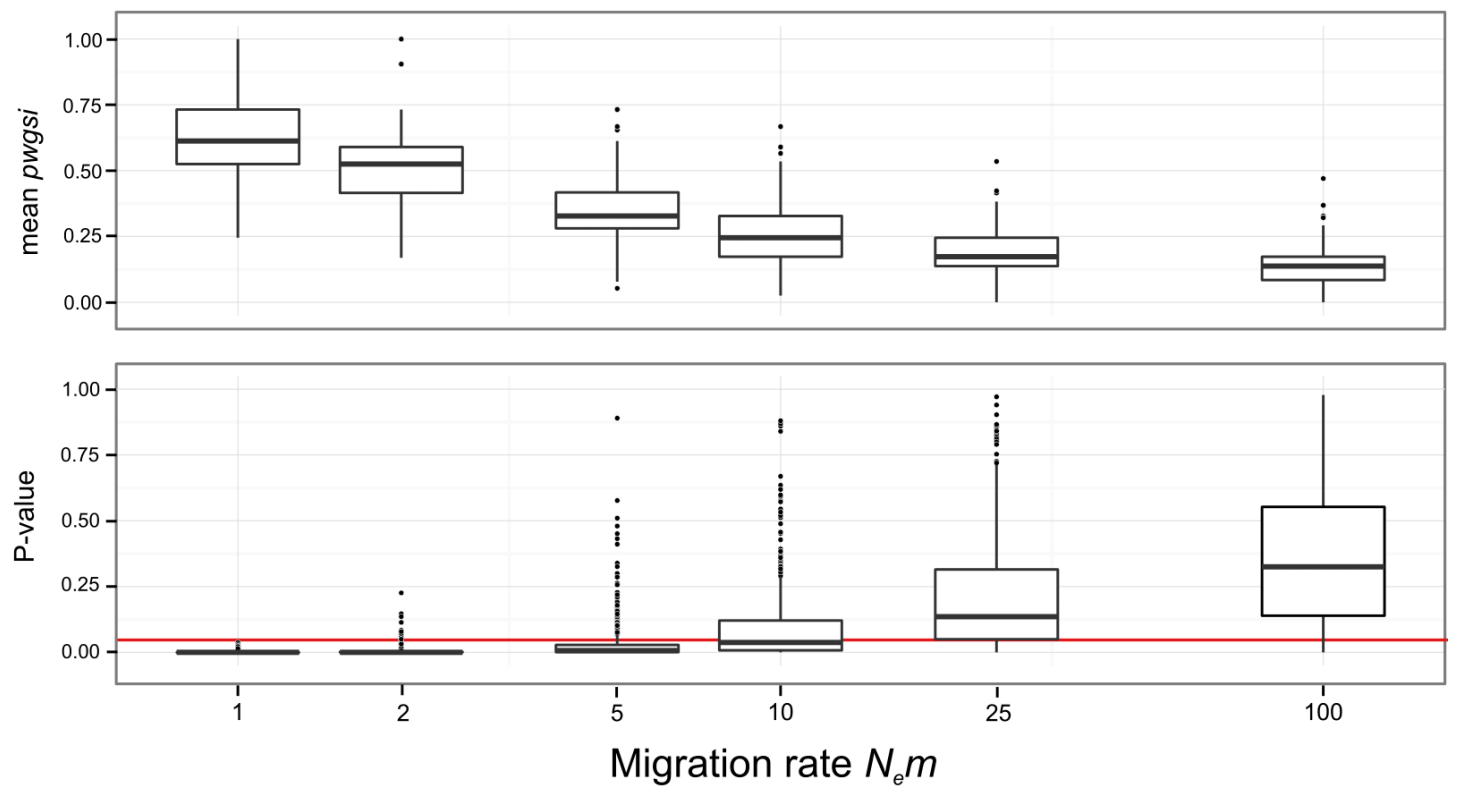

509

\section{$510 \quad$ Figure 7}

$511 \quad$ The pwgsi measures population structure as well as lineage divergence.

512 Above: In the top panel, boxes represent distributions of pwgsi for the groups "a" and "b",

513 which were sampled from populations experiencing gene flow at a constant rate which varies along

514 the $x$-axis (large values of $N_{e} m$ correspond to more migration and thus less population-structure).

515 Below:. Boxes represent distributions of P-values obtained for the "a:b" comparison; red line the drawn at $P=0.05$. Note, note $\mathrm{x}$-axis is on a log-10 scale. 